\title{
Freud e os desdobramentos da questão histérica na história de Christoph Haizmann*1
}

\section{Freud and the developments of the hysterical issue in \\ Christoph Haizmann's case}

Sonia Leite*2

O trabalho visa, inicialmente, delinear algumas referências históricas sobre o tema da histeria, especialmente em sua perspectiva demológica e as "teorias" que articulam a ideia do demônio às "doenças da alma". A seguir resgata-se o artigo freudiano "Uma neurose demoníaca do século XVII", de 1923, quando Freud, a partir de seu interesse pela feitiçaria, possessões e fenômenos afins, dedica-se ao estudo do caso do pintor Christoph Haizmann que, acossado por convulsões e alucinações assustadoras, faz um pacto com o diabo. No referido trabalho, Freud estabelece as relações entre a figura do demônio e a figura paterna destacando uma questão fundamental para o estudo da histeria que servirá para as posteriores elaborações de Lacan sobre o tema.

Palavras-chave: Histeria, possessão, função do pai

*1 Esta é uma versão modificada do trabalho originalmente apresentado no VII Congresso Internacional de Psicopatologia Fundamental e XIII Congresso Brasileiro de Psicopatologia Fundamental, ocorrido de 8 a 11 setembro de 2016, em João Pessoa, PB, Brasil.

${ }^{* 2}$ Centro Psiquiátrico RJ/Universidade do Estado do Rio de Janeiro - UERJ (Rio de Janeiro, RJ, Brasil). 
No intuito de fazer uma reflexão sobre o tema da mesa $A$ histeria antes, durante e depois de Freud, idealizada pelo saudoso Manoel Berlinck para o Congresso de Psicopatologia Fundamental de 2016, fui estimulada a retomar o artigo freudiano "Uma neurose demoníaca do século XVII” (Freud, 1977b/1923[1922]). Tal artigo recebeu, em 1928, uma última versão modificada que foi produzida para o Congresso dos Bibliófilos Alemães, em Viena. O trabalho revela o interesse freudiano, que vinha de longa data, pela feitiçaria, possessões e fenômenos afins, e pela semelhança da história de Haizmann com a saga de Fausto de Goethe. Tal interesse se constituiu, especialmente, a partir da influência da obra de seu mestre Charcot e dos estudos realizados na Salpêtrière (1885-6). Merecem destaque duas cartas dirigidas a Fliess em 1897 (17 e 24 de janeiro), quando indica que "[...] a teoria medieval da possessão sustentada pelos tribunais eclesiásticos, era idêntica à nossa teoria de um corpo estranho e da divisão da consciência" (Masson, 1986, p. 225). Nessas linhas, vemos se antecipar a ideia de que nos fenômenos de possessão, da mesma forma que na histeria, a temática do Pai desempenha um lugar fundamental.

Considera-se, aqui, que aquilo que se revela nas reflexões freudianas diz respeito a uma espécie de metonímia paterna (Froemming, 2003) nas transformações da cultura, que desnuda a estreita ligação entre a escolha da neurose e o discurso dominante de cada época. Tendo em vista esses pontos e sem pretender esgotar o tema, resgato, aqui, alguns aportes da história da histeria em seus deslocamentos nos discursos da cultura, fundamentais para se pensar a clínica na atualidade. 


\section{Breve histórico sobre a histeria}

Como afirma Trillat (1991), ao longo dos séculos a histeria é uma problemática que tem sido reivindicada por diferentes poderes, estados e disciplinas, além de ter sido produtora de um imenso universo de conhecimento. O fato é que "o padre, o filósofo e o médico [...] sentiram-se concernidos num momento ou noutro, uns e outros e todos juntos" (p. 13), por essa questão.

Em sua origem greco-latina a histeria se constituiu como uma questão de e para as mulheres - as parteiras — que, à distância dos homens, acumulavam um saber sobre o parto, a infância, o sexo da mulher e as doenças que as acometiam, especialmente aquela traduzida pela sufocação. Sufocação da matriz, do útero - origem da palavra histeria.

Hipócrates (século IV a.C) vai consagrar 250 páginas de suas obras completas às "doenças das mulheres", cuja origem principal é atribuída à mobilidade da matriz, dando continuidade à ideia, que remonta à mais alta Antiguidade, de que o útero é um organismo vivo análogo a um animal dotado de autonomia e de deslocamento. Ideia insólita que terá vida longa até o começo da era cristã. A "sufocação da matriz" - a histeria — considerada apenas um caso particular das doenças das mulheres, afecção que, segundo Hipócrates, ocorre, sobretudo, àquelas que não têm relações sexuais, o que tornaria o útero mais leve e de mais fácil movimento, causando a seguir uma sufocação súbita da mulher ao interceptar as vias respiratórias. Considera que é por essa razão que o branco dos olhos revira, a mulher fica fria e lívida, e a saliva flui à boca fazendo-a sucumbir asfixiada se assemelhando aos ataques epilépticos. Descrição precisa daquilo que, muito mais tarde, Charcot vai nomear de ataque histérico completo. O tratamento indicado nesse período são as relações sexuais, os trabalhos manuais e as gestações que acalmariam o que seria uma atividade febril da cabeça. O que vale destacar é a ideia corrente nesse período de que a mulher se distingue do homem por essa característica singular de encerrar em seu ventre um animal que não tem alma (Trillat, 1991).

Somente à época romana, devido aos movimentos de libertação das mulheres e dos escravos, iniciaram-se algumas mudanças nos tratamentos bárbaros dirigidos às histéricas cujo objetivo era fazer descer o útero, que teria se deslocado em direção à cabeça (Trillat, 1991).

De um modo ou de outro, a violência tem acompanhado os chamados tratamentos dos sintomas histéricos: extirpação do útero, internações forçadas, ou mesmo a camisa de força química. O que se retrata, através dos tempos, 


\section{LITERATURA, ARTE, CULTURA}

é a intolerância dos discursos instituídos em relação à posição histérica, ou melhor, ao discurso da histérica, como ensina Lacan (1969-70/1992]), cujo agente é o sujeito dividido marcado pela falta (Leite, 2016).

A posteridade vai reter da herança médico-filosófica uma importante observação: que a história da histeria é estreitamente ligada à história da epilepsia. Tanto uma quanto a outra se traduzem em manifestações corporais espetaculares que inspiram desde o temor até a compaixão. A violência do ataque deixa o sujeito aturdido e inconsciente em relação ao que passou. Hipócrates, ao localizar a epilepsia no cérebro, destrói as crenças que a rondavam. A histeria, no entanto, teve que esperar alguns séculos para com Charcot, e depois com Freud, encontrar uma delimitação e um reconhecimento. Com as investigações charcottianas, as relações entre a histeria e o órgão genital feminino sofrerão uma transformação definitiva quando em suas apresentações de pacientes indicará que mesmo um "artesão vigoroso e sólido", assim como um "motorneiro de locomotiva" (Charcot, 1887-89/2003, p. 19) podem ser acometidos pela doença.

$\mathrm{Na}$ verdade, um longo caminho ainda seria percorrido até que essas ideias fossem introduzidas e o fato é que, durante toda a Idade Média, cerca de cem mil mulheres, designadas bruxas, foram queimadas vivas. A partir desse período, com Santo Agostinho, “[...] o gozo do sexo não poderá mais ser considerado um remédio, pois, a natureza, mãe de todos os seres vivos, não é (mais) um princípio de ordem" (Julien, 1996, p. 246). Ao contrário, a natureza passa a ser vista como enganosa, desordenada, em razão do mal introduzido pelo demônio e os sintomas somáticos tomados como um sinal do triunfo da maldade. O que se chamava histeria passa, então, durante toda a idade média, a ser considerada expressão de um fenômeno de possessão demoníaca.

Em consequência, a possessão é interpretada como um modo de contestar o poder do senhor (político e/ou religioso), a partir de um pacto com o demônio que adquire com isso um poder sobre os corpos. É vista, assim, como uma manifestação de uma influência de ordem erótica que tem como um dos principais sinais a anestesia de certas partes do corpo do enfeitiçado. A cura do fenômeno ficará a cargo dos exorcistas, enquanto a execução e a condenação caberão ao poder político que se efetiva, diante do povo, com uma finalidade educativa.

Dentro dessa lógica, o Papa Inocêncio VIII vai nomear dois dominicanos, os inquisidores H. Kramer e J. Sprenger, para julgar casos de bruxaria. Mais tarde, os dois publicarão Malleus Maleficarum - O manual das bruxas, em 1484 (Kramer \& Sprenger, 2015), que durante quatro séculos foi o guia oficial 
da Inquisição para a chamada caça às bruxas. Expressão que se firmou ao longo da história para descrever todas as situações de perseguição oriunda de poderes absolutos.

Freud reconheceu a enorme importância desse manual para a compreensão da histeria, revelando numa carta a Fliess (24 de janeiro de 1897) que o havia adquirido e que o estudava com muito afinco e interesse.

No século XVII, se estabelecerá uma verdadeira luta pela posse da histeria, campo de batalha entre religiosos e médicos, desencadeando um processo de dessacralização da temática revelando que, através dos tempos, a histeria tem se transvertido tanto numa questão sobrenatural quanto natural (científica).

Desse modo, três correntes distintas se constituem: 1) A organicista (Grã-Bretanha), que contesta a teoria uterina de Hipócrates, em nome da neurologia; 2) A psicogenista, com Sydenham (Grã-Bretanha) e Pinel (França), quando a histeria passa a ser vista como uma desordem das paixões e, portanto, curável; 3) E, como consequência, a partir do século XVIII, com Mesmer (França), Braid (Grã-Bretanha) e principalmente Charcot, com o nome de magnetismo, fluido ou sugestionabilidade, o que se evidencia é a afirmação do poder de cura da hipnose sobre os sintomas histéricos (Trillat, 1991).

Cada sintoma passa a ser visto como conjunto de sinais, cada um só tendo valor em relação aos demais, formando, assim, um quadro clínico (Charcot, 1887-89/2003). Nesse momento, apesar de a causa ainda ser pensada via hereditariedade (degenerescência), os sintomas são relacionados a agents provocateurs. Somente a partir de Freud e da psicanálise, a causa da histeria não será mais articulada à hereditariedade, mas ao funcionamento inconsciente apoiado no tema da sexualidade infantil.

Fazer a história da histeria revela a tendência de mutabilidade dos sintomas que não cessam de se transformar, acarretando inquietação nos especialistas. Multiplicidade que não se deixa capturar, mobilidade que é própria da máscara, o histérico "confunde os hábitos do pensamento social aceitos pondo à mostra os limites do saber vigente" (Julien, 1996, p. 246). Questão que a psicanálise retomará pela afirmação da não unidade e da não fixidez da identidade histérica.

O fato é que a histeria, tratada por padres e médicos, tem se constituído numa espécie de porta-voz daquilo que revela os limites e o impossível da cultura em cada época.

Com a exclusão da terminologia histeria a partir do DSM-III (Manual Diagnóstico e Estatístico de Transtornos Mentais), tal fenômeno, no entanto, 


\section{LITERATURA, ARTE, CULTURA}

vai reaparecer, repartido em vários transtornos, tais como os transtornos dissociativos, o transtorno bipolar etc., dando corpo à multiplicidade de sintomas que sempre caracterizou o sujeito histérico (DSM-5, 2014).

Caberia, no entanto, interrogar, seguindo P. Julian (1996), tendo-se em vista a presença da histeria ao longo da história: Para onde se deslocou a histeria na atualidade?

\section{Sobre a "neurose demoníaca"}

Logo no início do artigo, Freud faz uma importante colocação sobre a relação da psicopatologia com a cultura ao afirmar que "[...] nos dias de hoje (época apsicológica) as neuroses assumem um aspecto hipocondríaco e aparecem disfarçadas como enfermidades orgânicas" [...]. "Já as neuroses daqueles tempos antigos surgem em trajes demoníacos" (1923/1977b, p. 91). Ressalta, nesse trecho, a importância do campo social-cultural no fornecimento dos significantes que recobrem o mal-estar estrutural do sujeito. Tal temática foi posteriormente anunciada por Lacan, em 1967, quando assinala a questão da demanda do sujeito em direção ao Outro, destacando as transformações ocorridas no fenômeno da transferência, inicialmente, dirigida ao padre, como sujeito suposto saber e que se desloca a seguir, a partir das mudanças culturais e políticas, em direção ao médico e seu saber.

No referido artigo, Freud (1923/1977b) considera que os estados de possessão são oriundos da projeção dos estados mentais dos neuróticos histéricos que, posteriormente, com a psicanálise, serão compreendidos como fazendo parte da vida intrapsíquica. Descobre, nos primórdios da psicanálise, um vínculo simbólico entre o sintoma somático e sua causa considerada inicialmente como traumatismo psíquico, isto é, como experiência sexual prematura. O que se revela é que o histérico sofre de reminiscências inconscientes ligadas a um afeto insuportável. Freud descobre que os relatos de sedução do pai encobrem as lembranças recalcadas de uma atividade sexual própria. A histeria revela, assim, o infantilismo da sexualidade humana e as fantasias de desejo edipiano (incesto e parricídio). $\mathrm{O}$ enigma da diferença sexual confronta o sujeito humano com um impossível que o convoca à simbolização a partir da lei do pai.

A pesquisa freudiana sobre o caso do pintor Christoph Haizmann se origina a partir da descoberta pelo diretor de uma biblioteca em Londres de um manuscrito originário do santuário de Mariazell, no sudoeste de Viena, 
que relata com descrição minuciosa a redenção milagrosa de um pacto com o demônio, mediante a graça da Santa Virgem Maria. O diretor da biblioteca entrega uma cópia a Freud na busca de uma opinião de um especialista sobre o ocorrido.

O manuscrito descreve que Haizmann é tomado por convulsões assustadoras na igreja da aldeia em que vivia quando, então, é abordado pelo prefeito que busca identificar o que o oprimia e se ele havia assumido (algum) intercâmbio com o espírito maligno. (Freud acredita que já a partir desse momento pode ter sido sugerido ao pintor a fantasia de seu pacto com o demônio.)

O homem admite que nove anos antes, "[...] encontrando-se em estado de desalento quanto à sua arte e duvidoso sobre a possibilidade de se sustentar, entregara-se ao demônio, que o havia tentado nove vezes e dera-lhe seu compromisso por escrito de pertencer-lhe em corpo e alma [...]."'(Freud 1923/1977b, p. 95).

Freud levanta, então, a questão: em troca de que alguém entregaria a alma e o corpo ao diabo? Tal entrega significa, em última instância, um pacto de obediência ao mestre, absoluto. A palavra possessão, nesse sentido, traz exatamente a ideia do que se trata.

A busca de riqueza, segurança, gozo, enfim, seriam as razões mais frequentes. Freud, no entanto, vai identificar, nesse caso específico, que a razão do pacto tem relação com o fato de o pintor se encontrar num estado melancólico que o impedia de trabalhar e que a causa principal de seu desalento havia sido a morte do seu pai (1923/1977b, p. 103). Nesse sentido, o "compromisso" com o Diabo foi feito visando à libertação de um estado de depressão (p. 103), significando que o pintor se tornaria filho do Diabo por nove anos e ao final desse tempo se tornaria, então, sua propriedade definitiva.

Ante a morte do pai como elaborar seu luto? Freud conclui que diante da dificuldade de elaboração da perda o demônio surge como um substituto paterno. Para justificar sua hipótese, ele indica a primeira ilustração que o pintor faz da primeira vez em que o diabo lhe apareceu (imagem 1) "como um honesto cidadão de idade, de barbas castanhas, vestido com uma capa vermelha e apoiando-se com a mão direita numa bengala, com um cão negro ao lado" (1923/1977b, p. 109). Já nas demais ilustrações sua aparência torna-se cada vez mais terrificante ou mesmo mitológica, aparelhado com chifres, garras de águia e asas de morcego (imagem 2 e 3). Aqui, se revela, a principal característica do demoníaco e sua capacidade de transformação inquietante, como aquilo que é mutante, sem estabilidade, que se desloca e condensa rapidamente — sem lugar, sem corpo definido (Eco, 2007). 


\section{LITERATURA, ARTE, CULTURA}

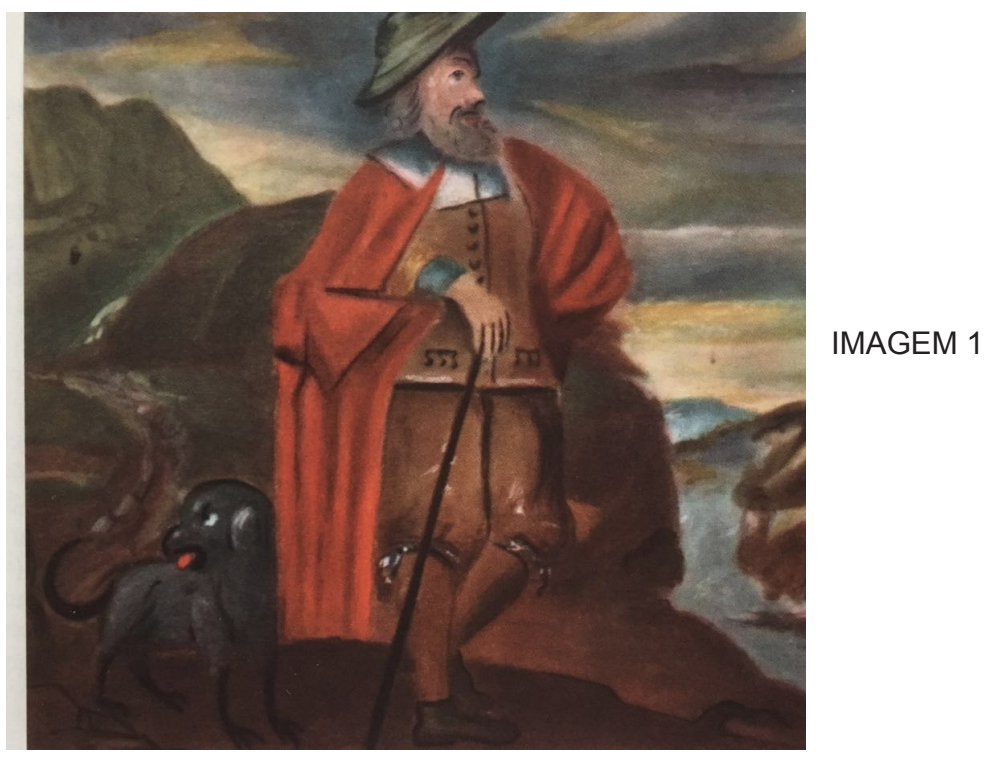

IMAGEM 2

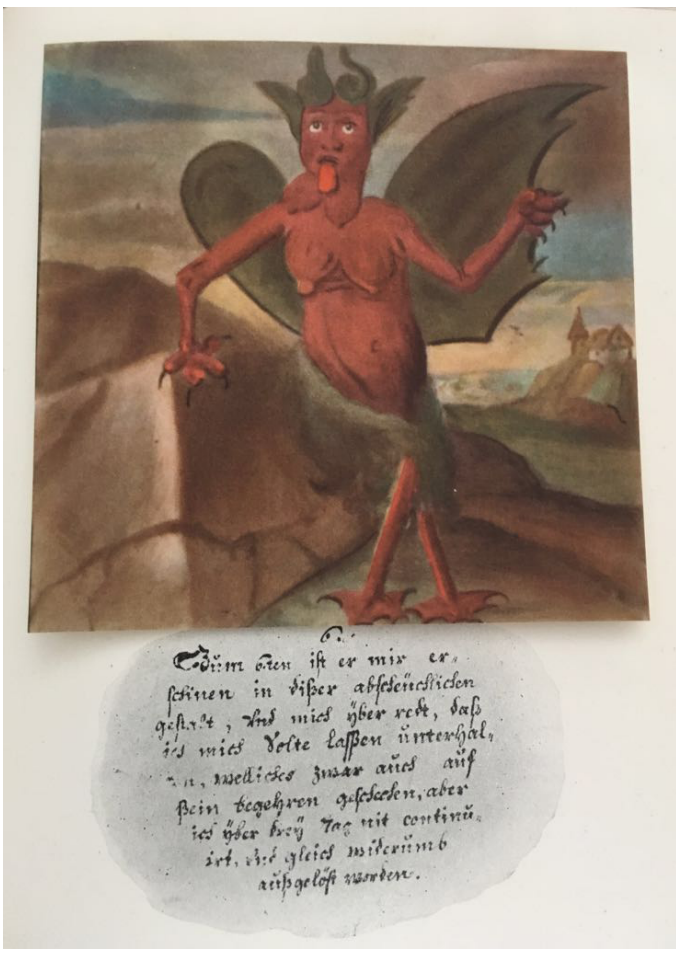




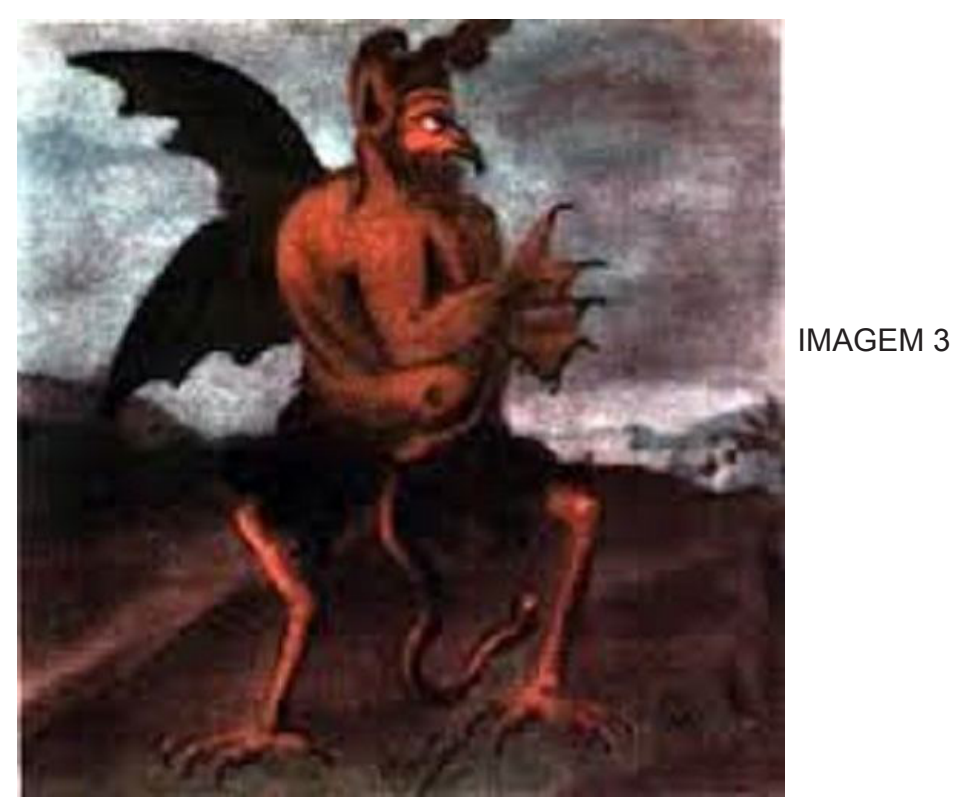

Freud sublinha que a representação do pai em Diabo, apesar de estranha, se relaciona com o fato de que Deus é um substituto paterno, um pai idealizado, perfeito, o pai tal qual é visto na infância. Posteriormente, o pai é tomado de uma forma diferente, menor e, muitas vezes, degradada. O fato é que a relação com o pai é ambivalente desde o início da vida. Ou seja, Deus e o Demônio são originariamente idênticos e vinculados à figura paterna.

No caso do nosso pintor, Freud identifica a presença de uma forte ambivalência que é confirmada pelo fato de o luto em relação à perda do pai não se processar, gerando uma experiência melancólica.

Destaca que aquilo contra o qual o pintor se rebela é a posição feminina em direção ao pai que culmina com a fantasia de dar-lhe um filho após nove anos (que seria o correspondente dos nove meses). Os aspectos femininos do Demônio, que aparecem na série de pinturas, seriam, assim, uma forma de projeção da própria feminilidade repudiada pelo pintor. Temos então no "pacto" a presença do amor ao pai e, simultaneamente, uma revolta contra a fantasia feminina em relação ao pai, ou seja, contra a castração. Tanto a projeção no demônio de aspectos femininos, assim como o recurso às graças da Virgem Maria para se curar, revelam o que Freud denomina de uma fixação prévia na relação com o Outro materno. Como indica: “[...] se a repugnância 


\section{LITERATURA, ARTE, CULTURA}

de nosso pintor de aceitar a castração lhe tornou impossível apaziguar seu anseio pelo pai, é perfeitamente compreensível que se tenha voltado para a imagem da mãe em busca de auxílio e salvação" (Freud, 1923/1977b, p. 116).

Freud destaca que depois de uma segunda crise, Haizmann acaba por ingressar na Ordem dos Irmãos Hospitalários. Tal decisão é também uma solução para a origem da sua doença e para a sua sensação de incapacidade de ser independente e de trabalhar em função da depressão (Freud, 1923/1977b, p. 130). O que se revela é a necessidade de ser nutrido por alguém: verifica-se, assim, um deslocamento que vai do pai ao demônio como substituto paterno, aos piedosos padres da Igreja (p. 132). Freud conclui que aqui se expõe a dinâmica da neurose: uma libido não pode ser satisfeita, logrando êxito com auxílio de uma regressão a fixações antigas, encontrando, assim, a possibilidade de descarga do inconsciente recalcado (p. 132).

O trabalho de pesquisa freudiano nesse texto marca também sua importância ao exemplificar um caso de histeria masculina, como já havia feito Charcot. Coloca assim em destaque que é a posição do sujeito (homem ou mulher), diante de duas questões principais - o amor-ódio pelo pai e o enigma do feminino - que determinam os sintomas na histeria.

Haizmann, no estudo freudiano, nos apresenta um impasse subjetivo diante da castração: não aceitar a castração nem do lado masculino, retrocedendo ante o enfrentamento com o pai, nem do lado feminino retrocedendo ante a implicação de uma posição feminina em relação ao pai (Bruno, 1886/1986). Vale destacar que uma diferença fundamental entre a histeria feminina e a masculina é a presença, nessa última, da intensidade do ódio ao pai no complexo de Édipo, fato que ativa ainda mais a ambivalência e, consequentemente, a culpa.

\section{Para concluir, algumas questões}

Conforme considera Lacan, na década de 1970: "Meu dizer que o inconsciente é estruturado como uma linguagem não é do campo da linguística" (1972-73/1985, p. 25). Essa afirmação o leva a criar o neologismo linguisteria, junção das palavras linguística e histeria para marcar, assim, uma distância em relação à linguística no seu sentido estrito, enfatizando que a linguagem do inconsciente é da ordem do sintoma histérico, ou, ainda, tem nesse quadro sua mais clara expressão. 
Linguisteria é uma forma de alusão ao fato de que a linguagem do inconsciente é uma espécie de fenômeno conversivo que fala por si só, "língua" inscrita e enraizada no corpo do falante, uma incrustação de significantes no corpo (Peixoto, 2009). Em outras palavras, aquilo que dá corpo ao corpo.

Ao estabelecer esses pontos Lacan retira, definitivamente, a histeria de um lugar de doença para situá-la, radicalmente, como condição do sujeito falante.

A questão freudiana se ocupa em pensar como se articulam as formações do inconsciente na histeria. É o próprio estatuto do objeto que é revisto, pois o objeto do desejo não é o da necessidade e nem o da demanda, mas desejo de um desejo que incide sobre a falta no Outro. Considera, nesse sentido, que na histeria há um apelo ao desejo puro.

Diante do impasse "sou uma mulher? sou um homem?" o que se revela é a problemática da identificação ao gênero. Identificação que seria, de algum modo, utilizada como tentativa de dar solução à angústia de castração, promovendo, assim, alguma estabilização. Tal é o caso da famosa paciente de Freud (1905/1977a), Dora, que busca uma resposta para a pergunta "o que é uma mulher?". Dora, efetivamente, aprecia e se interessa pela sra. K, por atribuir a 160 ela o segredo da feminilidade, enquanto o sr. K lhe serve de apoio identificatório nessa empreitada. Dessa descrição freudiana, Lacan faz uma releitura estrutural, onde a histeria passa a ser definida pela posição do sujeito em relação ao desejo do Outro. E isto segundo uma dupla vertente: por um lado, ela se coloca como passiva diante desse desejo, pois esse desejo é o que pode constituí-la como fálica; por outro, a necessidade de manter o desejo insatisfeito exige do sujeito histérico uma atividade constante, pois há sempre o risco de que o outro atenda o desejo e abandone sua função estabilizadora na estrutura.

Os avanços de Lacan em torno do tema da gramática desejante da histeria demonstram que esta se transforma num verdadeiro paradigma contemporâneo. Seja para nomear a posição de demanda do analisante, no início de sua análise, seja para descrever o estilo metonímico de seu desejo no final desta, Lacan passa a compreender a histeria como uma estrutura discursiva que transcende, portanto, seu uso como entidade psicopatológica. Destaca-se, aqui, o que foi sem dúvida a mais importante contribuição lacaniana para o conceito de histeria, ao defini-la como uma forma de discurso ao lado do discurso do mestre, do discurso do universitário e do discurso do analista, constituindose como uma modalidade de laço social. Ao criar os quatro discursos, Lacan encontra uma resposta aos acontecimentos sociopolíticos de maio de 1968, que serão introduzidos no seminário 17 (1969-70/1992). 


\section{LITERATURA, ARTE, CULTURA}

Trata-se, portanto, de um importante instrumento conceitual para pensar a ação do psicanalista no socius e a aposta no desejo como orientador do sujeito, temática introduzida num momento histórico em que o mal-estar na cultura se acentuava. Mais adiante, inventa a escrita do discurso do capitalista para indicar que algo aí caminha sobre rodas, ou seja, que anda rápido demais, que se consome tão bem até o ponto em que se consuma (Lacan, 1967/1972) e não faz laço social.

Destaca, assim, a ideia de "consumismo" e "consumição" apontando um sistema que favorece tanto o consumo exagerado quanto o ato de consumir-se, mortificar-se. Em outras palavras, os gadgets, as quinquilharias e as demandas de consumo em geral deixam as pessoas completamente à mercê dos objetos, à deriva e impossibilitadas de exercer, de fato, suas escolhas desejantes.

Por um lado, na clínica a medicalização se radicaliza como resposta ao mal-estar contemporâneo e o consumo de remédios segue a lógica do discurso capitalista. Por outro, a ideia de uma instabilidade constante, de uma fluidez dos espaços sociais e da mudança na experiência do tempo parece questionar aquilo que seria o formalismo e a evidência clínica que tudo estabilizaria. Novas formas sociais são construídas. Deformar a realidade, buscar o elementar aí encoberto e desfazer uma realidade absoluta, assim como as ideias e os conceitos, como indica Umberto Eco (2007), é um modo de questionamento da exclusão do estranho e do feio, abrindo lugar para o disforme e o não normatizável. De fato, verifica-se na atualidade uma crítica política realizada pelos pequenos grupos identitários que se dirige a certo modelo de vida burguês estável. Critica que abre espaço para a afirmação de comportamentos e escolhas que a princípio seriam "inconvenientes". Resposta ao capitalismo que "tudo devora", massifica e homogeneiza?

Considerar os desdobramentos da histeria na atualidade, para além de reafirmarmos sua presença no cotidiano da clínica, nos leva a reencontrá-la como modalidade privilegiada de laço social, que se impõe como resposta aos principais impasses oriundos do mal-estar cotidiano. É nesse sentido que encontramos, por exemplo, a questão dos gêneros, no plural, que se apresenta cada vez mais no tecido social expressando claramente aquilo que seria da ordem da diversidade e da multiplicidade como estrutural ao sujeito.

$O$ fato é que o discurso da histeria permite compreender a lógica presente em cenas mais amplas da vida social, onde, por exemplo, posições de demanda, provocação ou sedução, antes ocupadas pelo demoníaco da idade média, são encarnadas por indivíduos ou por pequenos grupos que reivindicam seus direitos diante de representantes de saberes oficiais. 
Então o demoníaco está à solta? Ontem, hoje e sempre o discurso da histeria se afirma, na busca de novos significantes que respondam ao mal-estar na sociedade, questionando os saberes instituídos. E talvez seja, aqui, no nível mais complexo de potencial político de funcionamento como laço social que a histeria possa ser reencontrada em sua mais instigante presença nos dias de hoje.

\section{Referências}

American Psychiatric Association (2014). Manual Diagnóstico e Estatístico de Transtornos Mentais - DSM-5 (Tradução de Maria Inês Corrêa Nascimento et al., $5^{\mathrm{a}}$ ed.). Porto Alegre, RJ: Artmed.

Bruno, P. (1986). La histeria masculina. In Quarto Encuentro Internacional del Campo Freudiano: Histeria y Obsesión. Buenos Aires, Argentina: Manantial. (Trabalho original publicado em 1886).

Charcot, J. M. (2003). Grande histeria. Rio de Janeiro, RJ: ContraCapa/Rios Ambiciosos. (Trabalho original publicado em 1887-1889).

Eco, U. (2007). A história da feiura. Rio de Janeiro, RJ: Record.

Froemming, L. S. (2003, agosto). A metonímia paterna - considerações sobre a figura do demônio. Correio APPOA - Uma neurose demoníaca do século XVII(116), 12-16.

Freud, S. (1977a). Fragmentos da análise de um caso de histeria. In Edição Standard Brasileira das Obras Psicológicas Completas de Sigmund Freud (v. VII, pp. 1-119). Rio de Janeiro, RJ: Imago. (Trabalho original publicado em 1905).

Freud, S. (1977b). Uma neurose demoníaca do século XVII. In Edição Standard Brasileira das Obras Psicológicas Completas de Sigmund Freud (v. XIX, pp. 87133). Rio de Janeiro, RJ: Imago. (Trabalho original publicado em 1923).

Julien, P. (1996). Histeria. In P. Kaufmann, Dicionário enciclopédico de psicanálise - o legado de Freud e Lacan. Rio de Janeiro, RJ: Jorge Zahar.

Kramer H.; Sprenger, J. (2015). O martelo das feiticeiras. Rio de Janeiro, RJ: Rosa dos Tempos.

Lacan, J. (1972). Intervenção sobre a exposição de P. Lemoine: A propósito do desejo do médico. Apresentado no Congresso da Escola Freudiana de Paris sobre A técnica psicanalítica, Aix-en-Provence, França, 1967. Lettres de l'École freudienne, 9, 68-78.

Lacan, J. (1985). O seminário. Livro 20. Mais ainda. Rio de Janeiro, RJ: Jorge Zahar. (Trabalho original publicado em 1972-73). 


\section{LITERATURA, ARTE, CULTURA}

Lacan, J. (1992). O seminário. Livro 17. O avesso da psicanálise. Rio de Janeiro, RJ: Jorge Zahar. (Trabalho original publicado em 1969-70).

Leite, S. (2016). Histeria de conversão, ainda? In S. Leite, \& T. Costa (Orgs.), Letras do sintoma. Rio de Janeiro, RJ: Contra Capa.

Masson, J. M. (1986). A correspondência completa de Freud-Fliess. Rio de Janeiro, RJ: Imago.

Peixoto, E. (2009.maio-out.). Linguisteria: por trás do que se diz. Revista Eletrônica do Núcleo Sephora, IV(8), 88-95, Recuperado em 5 jan. 2019, de: <http://www. isepol.com/asephallus/numero_08/revista_8.pdf $>$.

Trillat, E. (1991). História da histeria. São Paulo, SP: Escuta.

\section{Resumos}

(Freud and the developments of the hysterical issue in Christoph Haizmann's case)

Initially, this paper aims to outline some historical references about hysteria, especially from its demonological perspective and regarding the "theories" which associate the idea of 'demon' to 'illnesses of the soul'. We take into account Freud's paper 'A seventeenth-century demonological neurosis' (1923), written in a time when Freud examined witchcraft, possessions and other phenomena and analyzed Christoph Haizmann's case who, harassed by convulsions and frightening hallucinations, makes a deal with the devil. In that paper, Freud associates the figure of the demon to the figure of the father, outlining a fundamental question for the studies on hysteria, which will serve for Lacan's developments about that subject.

Key words: Hysteria; possession; function of the fathe

(Freud et les développements de la question hystérique dans le cas de Christoph Haizmann)

Cet article vise initialement à délimiter certaines références historiques concernant le thème de l'hystérie, notamment en ce qui concerne sa perspective démonologique et les 'théories' qui lient l'idée du démon aux 'maladies de l'âme'. Ensuite on reprend l'article de Freud "Une névrose démoniaque au XVIIe siècle » rédigé en 1923, lorsque Freud, étant donné son intérêt pour la sorcellerie, les possessions et les phénomènes apparentés, se consacre à l'étude du cas du peintre Christoph Haizmann qui, souffrant de convulsions et d'hallucinations effrayantes, fait un pacte avec le diable. Dans cet article, Freud établit les rapports entre la figure du démon et la figure paternelle en soulignant un enjeu fondamental pour l'étude de l'hystérie qui servira aux élaborations postérieures de Lacan sur ce thème.

Mots clès: Hystérie, possession, fonction du père 
(Freud y el desarrollo de la cuestión de la histeria en la historia de Christoph Haizmann)

Inicialmente, el trabajo tiene como objetivo delinear algunas referencias históricas sobre el tema de la histeria, especialmente en su perspectiva demonológica y las "teorías" que articulan la idea del demonio a las "enfermedades del alma". A continuación, se rescata el artículo freudiano "Una neurosis demoníaca del siglo XVII”, de 1923, cuando Freud, a partir de su interés por la hechicería, posesiones y fenómenos similares, se dedica a estudiar el caso del pintor Christoph Haizmann que, atormentado por convulsiones y alucinaciones atemorizadoras, hace un pacto con el diablo. En el referido trabajo, Freud establece las relaciones entre la figura del demonio y la figura paterna destacando una cuestión fundamental para el estudio de la histeria, cuestión que servirá para las posteriores elaboraciones de Lacan sobre el tema.

Palabras clave: Histería, posessión, función del padre

(Freud und die Dimensionen der Hysterie im Fall von Christoph Haizmann)

Der vorliegende Artikel beschreibt zunächst einige historische Aspekte zum Thema der Hysterie, insbesondere die dämonologische Dimension und die "Theorien", welche die Idee des Teufels mit den "Seelenkrankheiten" verknüpfen. Freuds Artikel „Eine Teufelsneurose im siebzehnten Jahrhundert" (1923), verfasst in einer Zeit als Freud sich für Hexerei, Besessenheit und verwandte Phänomene interessierte, untersucht den Fall des Malers Christoph Haizmann. Da dieser an Krämpfen und furchterregenden Halluzinationen litt, schloss er einen Pakt mit dem Teufel. In seinem Artikel erörtert Freud die Beziehungen zwischen der Figur des Teufels und der väterlichen Figur, wobei er eine grundlegende Frage für das Studium der Hysterie hervorhebt, die den späteren Ausführungen von Lacan zu diesem Thema dienen wird.

Schlüsselwörter: Hysterie, Besessenheit, Funktion des Vaters

Citação/Citation: Leite, S. (2019, março). Freud e os desdobramentos da questão histérica na história de Christoph Haizmann. Revista Latinoamericana de Psicopatologia Fundamental, 22(1), 150-165. http://dx.doi.org/10.1590/1415-4714.2018v22n1p150.9.

Editores do artigo/Editors: Profa. Dra. Ana Maria G Raimundo Oda

Submetido/Submitted: 28.1.2019/ 1.28.2019 Aceito/Accepted: 10.2.2019 / 2.10.2019 


\section{LITERATURA, ARTE, CULTURA}

Copyright: (C) 2009 Associação Universitária de Pesquisa em Psicopatologia Fundamental/ University Association for Research in Fundamental Psychopathology. Este é um artigo de livre acesso, que permite uso irrestrito, distribuição e reprodução em qualquer meio, desde que o autor e a fonte sejam citados / This is an open-access article, which permits unrestricted use, distribution, and reproduction in any medium, provided the original authors and sources are credited.

Financiamento/Funding: Este trabalho não recebeu financiamento / This work received no funding.

Conflito de interesses/Conflict of interest: A autora declara que não há conflito de interesses / The author declares that there is no conflict of interest.

\section{Sonia LeITe}

Psicóloga; Psicanalista; Coordenadora Adjunta da Residência Multiprofissional em Saúde Mental (RMSM) SES/UERJ (Rio de Janeiro, RJ, Br); Professora e supervisora da RMSM; Doutora em Psicologia Clínica pela Pontifícia Universidade Católica do Rio de Janeiro PUC/RJ (Rio de Janeiro, RJ, Br); Editora da Revista Latinoamericana em Psicopatologia Fundamental; Membro do Corpo Freudiano Escola de Psicanálise Seção RJ; Coordenadora de Ensino do Corpo Freudiano Escola de Psicanálise - Seção Rio de Janeiro.

Rua Conde de Bonfim, 232/712

20520-051 Rio de Janeiro, RJ, Br.

https://orcid.org/0000-0002-3898-088X

soniacleite@uol.com.br

This is an open-access article, which permits unrestricted use, distribution,

(cc) BY-NC and reproduction in any medium for non-commercial purposes provided the original authors and sources are credited. 